\title{
VaR PREDICTION FOR GARCH $(1,1)$ MODEL WITH NORMAL AND STUDENT-t ERROR DISTRIBUTION
}

\author{
Novi Permata Indah ${ }^{1 *}$, Dian Permata Sari ${ }^{2}$, I Putu Eka Wijaya ${ }^{3}$, and Madjidainun Rahma ${ }^{4}$ \\ ${ }^{1,2}$ Management Study Program, Faculty of Economics, Universitas Singaperbangsa Karawang, Karawang, Indonesia \\ ${ }^{3}$ Agribusiness Study Program, Faculty of Agriculture, Universitas Singaperbangsa Karawang, Karawang, Indonesia \\ ${ }^{4}$ Accounting Study Program, Faculty of Economics, Universitas Singaperbangsa Karawang, Karawang, Indonesia \\ *Email: novi.permata@fe.unsika.ac.id
}

Accepted: January 17, 2022. Approved: January 17, 2022. Published: January 20, 2022

\begin{abstract}
This study aims at determining the estimated parameters of the GARCH (1.1) model establishing the prediction of the VaR value, and defining the accuracy of the VaR prediction. In this study, the error in the GARCH $(1,1)$ model uses a normal distribution and student-t distribution. The research method focuses on parameter calculation and the prediction of $\mathrm{VaR}$ value within two aspects regarding analytic and numeric aspects. Analytically, the prediction of the VaR value and the accuracy of the prediction of VaR value through the VaR coverage opportunity. It isn't easy to estimate the parameters for the GARCH (1.1) model analytically. Thus, the parameters are estimated numerically using the Quansi Newton optimization method. Prediction of VaR value and VaR coverage probability will be simulated numerically by using stock return data of IBM, INDF.JK and GSPC. The results show that the GARCH (1.1) model can model stock returns for IBM, INDF.JK and GSPC. There is no significant difference between the GARCH $(1,1)$ model with a normally distributed error and GARCH $(1,1)$ with a student-t distribution error in determining the prediction of VaR values. The numerical simulation results show that the VaR value prediction using the GARCH $(1,1)$ model with a normally distributed error is more accurate than the student-t-distributed error.
\end{abstract}

Keywords: GARCH Model, Value at Risk, Coverage Probability

\section{INTRODUCTION}

Nowadays, the stock market has turned into one of the exciting research objects. The trigger of stock prices is used as a country's economic health barometer [1]. The stock market itself means that it is closely related to investment. The returns obtained by an investor in the stock market are known as asset returns. Asset return is the rate of return of an investment over a certain period [2]. Asset returns in various countries generally show the phenomenon of time-varying volatility [3-5]. This situation indicates a relatively 'calm' return period which then changes to a 'turbulent' period. The following studies carried out to date concerning unconditional volatility from stock futures (see for example [6] and 7]).

Return behavior information is not enough to analyze financial time series data. Consequently, the term volatility appears. Volatility remains a measure of the spread of the magnitude of changes in the price of a financial instrument. In other words, volatility measures how much and how quickly the value of a financial instrument changes. Generally, the volatility of time series data is assumed to be constant over time. However, economic time series data volatility can change over a certain period. This change was caused by the financial market's reaction to various kinds of disturbances, including deteriorating political conditions, economic crises, wars, natural disasters, and others [8]. It assumes that the volatility of the financial time series data is not constant.

Volatility modeling has a significant role in the financial sector, especially in risk management.
Volatility modeling can be used to calculate the maximum loss from an asset return that can be tolerated with a certain level of significance within a certain period [9]. A good volatility model is a model that can accommodate the properties of asset returns and volatility [10-11]. One of the good volatility models in modeling stock return volatility is the Generalized Autoregressive Conditionally Heteroscedastic (GARCH) model [12]. This model states that volatility is a visual function determined by observations and the volatility of the last time by Research on GARCH volatility modeling [13-15].

The loss towards return is related to a measure of risk. Through the GARCH volatility model, the risk of investment loss can be estimated and measured. One measure of risk that can be used in estimating the magnitude of trouble in the GARCH model is Value at Risk (VaR). VaR is a measure of market risk that has been widely used for financial risk management, including in banking institutions, regulators, and portfolio managers [15 ].

This research determines the predictive value of value at risk analytically and numerically. Numerical calculation displays the estimated parameter GARCH $(1,1)$ with an normally distributed error and student-t. In addition, numerical calculations will define the prediction of the $\mathrm{VaR}$ value for the GARCH $(1,1)$ model with normal and student-t distribution errors and the accuracy of the prediction through the correct VaR proportion. 


\section{RESEARCH METHOD}

The risk of financial assets in the form of stock investments can be measured by using volatility. A risk is a form of investor loss when investing in the stock market. The volatility model is a way to predict volatility in the stock market. The GARCH (1.1) volatility model can capture the volatility of the financial time series [12][17-18]. Therefore, predictions of volatility models are needed to protect financial assets in the future [16]. In this study, the focus is on finding the parameter estimation of the GARCH $(1,1)$ model that fits the definition given by Bollerslev.

The definition of Bollerslev (1986), for instance $\left\{Y_{t}, t \geq 0\right\}$, is a stochastic process that states the return of asset time $\left\{Y_{t}, t \geq 0\right\}$ following GARCH $(1,1)$ model if:

$$
Y_{t}=\sigma_{t} \varepsilon_{t}, \quad \sigma_{t}^{2}=\alpha_{0}+\alpha_{1} Y_{t-1}^{2}+\beta_{1} \sigma_{t-1}^{2}
$$

with assumptions:

1. $\alpha_{0}>0, \alpha_{1} \geq 0, \beta_{1} \geq 0$ and the stationary

condition $\alpha_{1}+\beta_{1}<1$

2. $\varepsilon_{t} \sim \operatorname{iid} \mathrm{F}(0,1)$

3. $\sigma_{t}$ and $\varepsilon_{t}$ free each other.

4. $Y_{t-1}$ and $\varepsilon_{t}$ free each other.

This GARCH $(1,1)$ model follows the Markov process where the return value at time $t$ only depends on the return time value $(t-1)$. Thus the conditional expectation is $E\left[Y_{t} \mid Y_{t-1}\right]=0$, and the conditional variance is $\operatorname{Var}\left[Y_{t} \mid Y_{t-1}\right]=\sigma^{2}$. If the values of $Y_{t-1}$ and $\sigma_{t-1}$ are known, the value of $\sigma_{t}$ is a constant. The $Y_{t} \mid Y_{t-1}$ is the same as the distribution of $\varepsilon_{t}$ with a mean of zero and a variance of $\sigma^{2}$. Based on this, then we can determine the return value at risk of $Y_{t+1}$ as follows:

$$
\begin{aligned}
\operatorname{VaR}_{\alpha}^{t+1} & =E\left[Y_{t+1} \mid Y_{t}\right]+F^{-1}(\alpha) \sqrt{\operatorname{VaR}\left[Y_{t+1} \mid Y_{t}\right]} \\
& =F^{-1}(\alpha) \sqrt{\alpha_{0}+\alpha_{1} Y_{t}^{2}+\beta_{1} \sigma_{t}^{2}}
\end{aligned}
$$

The prediction of $\mathrm{VaR}$ is known if the random sample $Y_{1}, Y_{2}, \ldots, Y_{t}$ is

$$
\operatorname{VaR}_{\alpha}^{t+1}=F^{-1}(\alpha) \cdot \sqrt{\hat{\alpha}_{0}+\hat{\alpha}_{1} Y_{t}^{2}+\hat{\beta}_{1} \sigma_{t}^{2}}
$$

Furthermore, to determine the accuracy of the VaR prediction obtained in equation (1), a VaR accuracy test is carried out by determining the coverage probability. This coverage opportunity is expected to be close to the given confidence level. The probability of $\mathrm{VaR}$ coverage for return in the GARCH $(1,1)$ model is

$$
\begin{aligned}
P\left(Y_{t+1} \leq \operatorname{VaR}_{\alpha}^{t+1} \mid Y_{t}=y_{t}\right)= & P\left(\sigma_{t+1} \varepsilon_{t+1} \leq F^{-1}(\alpha) \cdot \sqrt{\hat{\alpha}_{0}+\hat{\alpha}_{1} Y_{t}^{2}+\hat{\beta}_{1} \sigma_{t}^{2} \mid Y_{t}=y_{t}}\right) \\
& =P\left(\varepsilon_{t+1} \leq F^{-1}(\alpha) \cdot \frac{\sqrt{\hat{\alpha}_{0}+\hat{\alpha}_{1} Y_{t}^{2}+\hat{\beta}_{1} \sigma_{t}^{2}}}{\sqrt{\alpha_{0}+\alpha_{1} Y_{t}^{2}+\beta_{1} \sigma_{t}^{2}}} \mid Y_{t}=y_{t}\right) \\
& =F\left(F^{-1}(\alpha) \cdot \frac{\sqrt{\hat{\alpha}_{0}+\hat{\alpha}_{1} Y_{t}^{2}+\hat{\beta}_{1} \sigma_{t}^{2}}}{\sqrt{\alpha_{0}+\alpha_{1} Y_{t}^{2}+\beta_{1} \sigma_{t}^{2}}} \mid Y_{t}=y_{t}\right) \\
& =E\left(F\left(F^{-1}(\alpha) \cdot \frac{\sqrt{\hat{\alpha}_{0}+\hat{\alpha}_{1} Y_{t}^{2}+\hat{\beta}_{1} \sigma_{t}^{2}}}{\sqrt{\alpha_{0}+\alpha_{1} Y_{t}^{2}+\beta_{1} \sigma_{t}^{2}}} \mid Y_{t}=y_{t}\right)\right) \\
& =\alpha+O\left(n^{-1}\right)
\end{aligned}
$$

The accuracy of the VaR prediction in the GARCH $(1,1)$ model that fits the data can also be seen from the correct VaR value [16]. The model is assumed to fit with the data if

$|\alpha-\hat{\alpha}| \approx 0$

Where $\hat{\alpha}_{\text {turns a proportion from return over }}$ VaR prediction. The GARCH $(1,1)$ parameter model $\hat{\alpha}_{0}, \hat{\alpha}_{1}, \hat{\beta}_{1}$ value can be measured through the likelihood maximum method. The estimation of the parameter values of the GARCH $(1,1)$ model in this study was carried out only numerically because it is very difficult to determine $\hat{\alpha}_{0}, \hat{\alpha}_{1}, \hat{\beta}_{1} \hat{\alpha}_{0}, \hat{\alpha}_{1}, \hat{\beta}_{1}$ with the Quasi-Newton optimization method.

The numerical simulation was carried out by using the MATLAB programming language. The data used in the numerical simulation is stock return data for International Business Machines Corporation (IBM.Inc), Indofood Sukses Makmur Tbk (INDF. $\mathrm{JK}$ ), and the S\&P 500 stock index ( GSPC). Data were taken from January 4, 2010, to December 31, 2013.

\section{RESULT AND DISCUSSION}

The results of numerical data processing from the three stock return data of International Business Machines Corporation (IBM.Inc), Indofood Sukses Makmur Tbk (INDF. JK), and the S\&P 500 stock index (GSPC) are presented in the following descriptive statistical table:

Table 1. Descriptive Statistics of Stock Return IBM, INDF.JK and GSPC

\begin{tabular}{ccccrrr}
\hline Stock & $\mathrm{n}$ & Mean & Variance & Skewness & Kurtosis & \multicolumn{1}{c}{ ACF(Lag 1) } \\
\hline IBM & 1006 & $3.4587 \times 10-4$ & $1.4295 \times 10-4$ & -0.6088 & 8.4349 & 0.0164 \\
INDF.JK & 1026 & $5.7068 \times 10-4$ & $4.2471 \times 10-4$ & -0.2697 & 6.7994 & 0.2015 \\
GSPC & 1006 & $4.8652 \times 10-4$ & $1.1443 \times 10-4$ & -0.4703 & 7.3579 & 0.2179 \\
\hline
\end{tabular}

Table 1 shows that the three stocks have a negative skewness where the histogram data is skewed to the left. It shows the stock return data for IBM, INDF.JK and GSPC have relatively high values. The kurtosis value of the three stocks is greater than three, so the distribution is leptokurtic (thick tail). INDF.JK and GSPC stocks have a significant autocorrelation in the first lag compared to IBM stocks, meaning that today's return is exceptionally influential on tomorrow. Of the three 
stocks, INDF.JK has the largest variance, meaning it is quite risky to invest in INDF.JK shares compared to IBM and GSPC shares.

Furthermore, numerical calculations will determine the parameter estimation of the GARCH
$(1,1)$ model by using stock return data of INDF.JK, IBM, and GSPC. The estimation results obtained can be seen in table 2 .

Table 2. Estimation of Stock Return Model Parameters IBM, INJF.JK and GSPC

\begin{tabular}{cccccc}
\hline Stock & Model & $\hat{\alpha}_{0}$ & $\hat{\alpha}_{1}$ & $\hat{\beta}_{1}$ & $\hat{v}$ \\
\hline INDF.JK & GARCH(normal) & $0.0334 \times 10-4$ & 0.1166 & 0.8522 & \\
& GARCH(t) & $0.0331 \times 10-4$ & 0.1248 & 0.8518 & 4.3311 \\
IBM & GARCH(normal) & $0.1962 \times 10-4$ & 0.1069 & 0.7615 & - \\
& GARCH(t) & $0.0756 \times 10-4$ & 0.0648 & 0.8845 & 4.1655 \\
GSPC & GARCH(normal) & $0.2154 \times 10-4$ & 0.1101 & 0.8395 & - \\
& GARCH(t) & $0.1977 \times 10-4$ & 0.1174 & 0.8480 & 5.1646 \\
\hline
\end{tabular}

Table 2 shows the stock of IBM, INDF.JK and GSPC have relatively small values. The value $\hat{\alpha}_{0}$ in the $\operatorname{GARCH}(1,1)$ model shows the mean reversion speed (the tendency of returns to approach the average value from time to time) [2]. Based on the GARCH model with an error normal distribution or GARCH (normal) on GSPC stock, the fastest is reaching out the mean $(4.8652 \times 10-4)$. The coefficient $\hat{\alpha}_{1}$ shows the magnitude of the influence of the previous time return value on today's return value, while the coefficient $\hat{\beta}_{1}$ shows the persistence of volatility. It means that the greater the value $\sigma_{t-1}$ , the greater the volatility at the time $t\left(\sigma_{t}\right)$, and so on. Thus, the volatility value from time to time tends to increase (there is persistence in volatility). $\alpha_{1}$ The fluctuates around the value of 0.05 , and the persistence coefficient $\left(\beta_{1}\right)$ ranges from 0.85 to 0.98 . In Table 2 , the values $\alpha_{1}$ are relatively small $\beta_{1}$ and relatively large $\hat{\alpha}_{1}+\hat{\beta}_{1}<1$. It shows that the GARCH $(1,1)$ model with normally distributed error and student-t for the three stocks is stationary and persistent. If the value of $\hat{\alpha}_{1}+\hat{\beta}_{1} \geq 1$, then the volatility of the model will increase indefinitely from time to time. It is very rarely the case with financial data, so it must be $\hat{\alpha}_{1}+\hat{\beta}_{1}<1$

The next stage will determine the prediction of Value at Risk from the returns of the three stocks using the GARCH $(1,1)$ model with a normal distribution error or GARCH (normal) and GARCH (1.1) with a student-t distribution error or abbreviated as GARCH (t). The VaR prediction uses $\alpha=99 \%, \alpha$ $=95 \%$ and $\alpha=90 \%$.

Table 3. The Prediction of VaR Value IBM Stock, INNDF.JK Stock and GSPC Stock at Time $\mathrm{t}+1$

\begin{tabular}{ccccc}
\hline Stock & Model & $V^{2} R_{99 \%}^{t+1}$ & $V a R_{95 \%}^{t+1}$ & $V a R_{90 \%}^{t+1}$ \\
\hline INDF.JK & GARCH(normal) & 0.0357 & 0.0253 & 0.0197 \\
& GARCH(t) & 0.0414 & 0.0240 & 0.0174 \\
IBM & GARCH(normal) & 0.0249 & 0.0176 & 0.0137 \\
& GARCH(t) & 0.0290 & 0.0167 & 0.0120 \\
GSPC & GARCH(normal) & 0.0153 & 0.0108 & 0.0084 \\
& GARCH(t) & 0.0173 & 0.0104 & 0.0077 \\
\hline
\end{tabular}

It can be seen that the difference in VaR predictions between the GARCH(normal) and GARCH (t) models is relatively small, namely $\pm 10-3$. It shows that the difference between the two volatility models is not significant in determining the VaR value. The VaR predictions for IBM, INDF.JK and GSPC stocks at time $1, \ldots, \mathrm{T}$ can be seen in Figure 1, Figure 2 and Figure 3. 

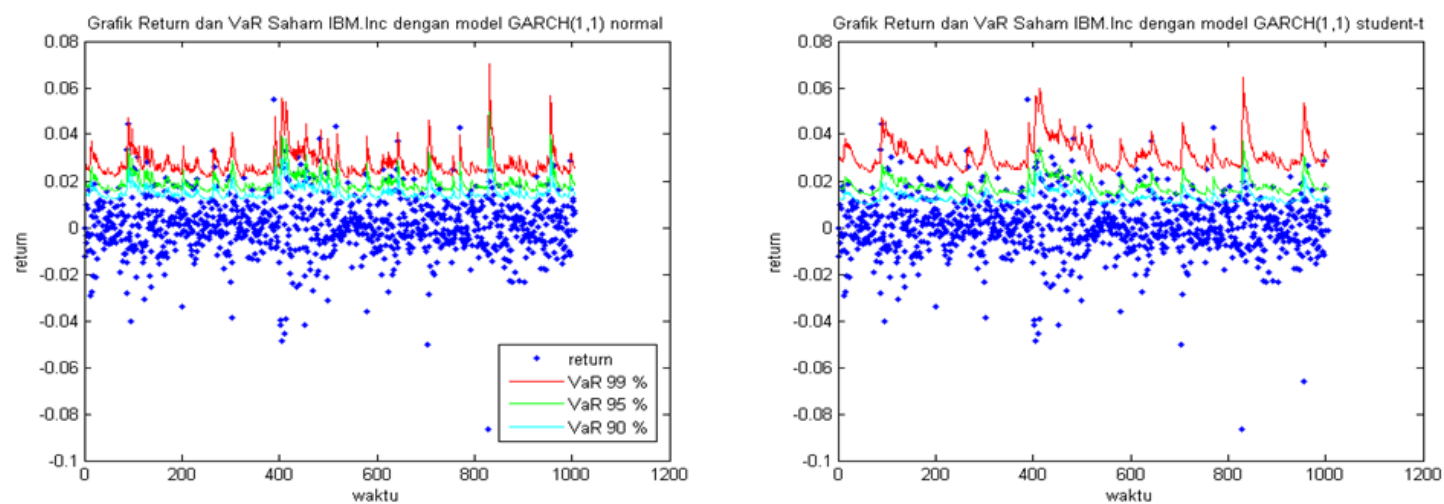

Figure 1. The Prediction of VaR Value of IBM Stock
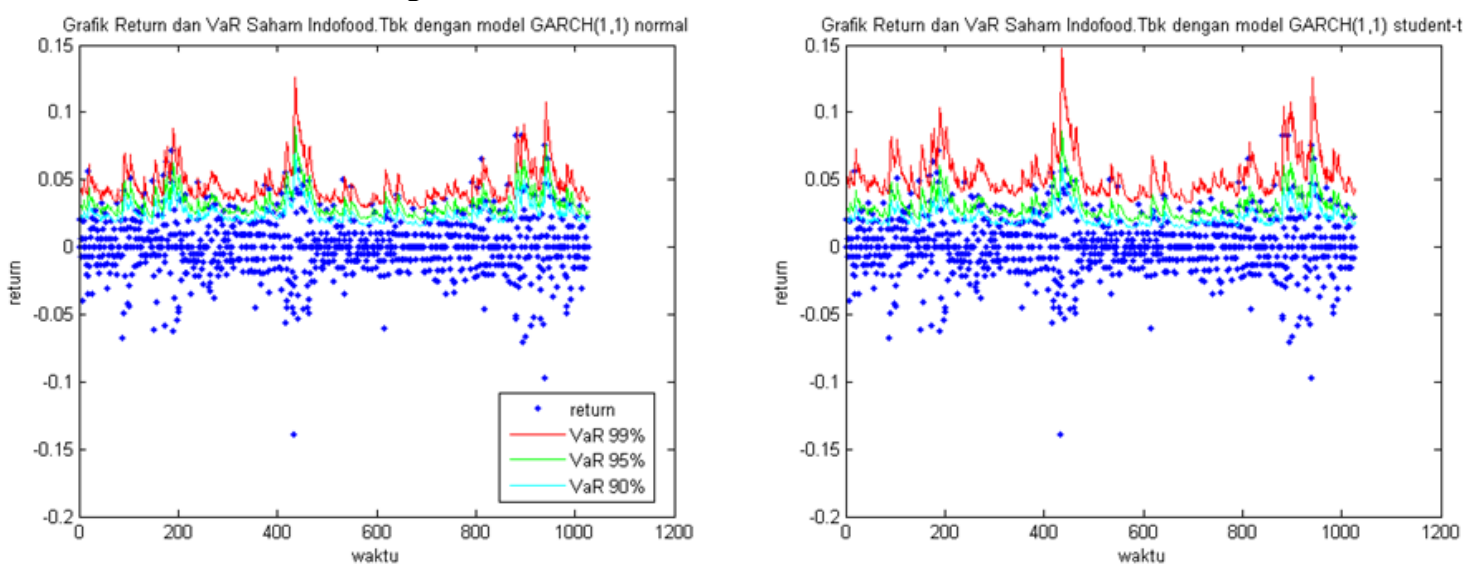

Figure 2. The Prediction of VaR Value of INDF.JK Stock
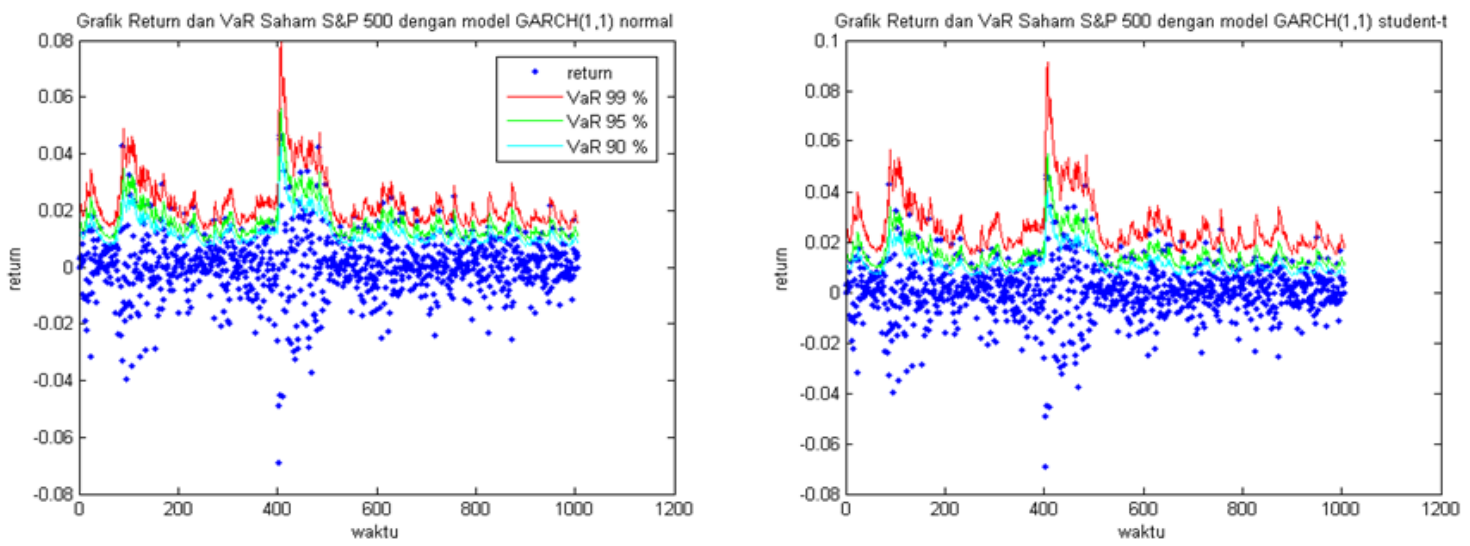

Figure 3. The prediction of VaR stock value of GSPC

Table 4. Correct VaR from IBM, INDF.JK and GSPC

\begin{tabular}{|c|c|c|c|c|}
\hline \multirow[t]{2}{*}{ Stock } & \multirow[t]{2}{*}{ Model } & \multicolumn{3}{|c|}{ Correct VaR } \\
\hline & & $99 \%$ & $95 \%$ & $90 \%$ \\
\hline \multirow[t]{2}{*}{ INDF.JK } & $\begin{array}{l}\text { GARCH } \\
\text { (normal) }\end{array}$ & $98.0 \%$ & $94.05 \%$ & $90.25 \%$ \\
\hline & $\operatorname{GARCH}(\mathrm{t})$ & $98.8 \%$ & $93.86 \%$ & $88.59 \%$ \\
\hline \multirow[t]{2}{*}{ IBM } & $\begin{array}{l}\text { GARCH } \\
\text { (normal) }\end{array}$ & $98.9 \%$ & $95.43 \%$ & $92.05 \%$ \\
\hline & GARCH(t) & $99.1 \%$ & $94.33 \%$ & $89.36 \%$ \\
\hline \multirow[t]{2}{*}{ GSPC } & $\begin{array}{l}\text { GARCH } \\
\text { (normal) }\end{array}$ & $98.6 \%$ & $95.03 \%$ & $90.85 \%$ \\
\hline & $\mathrm{GARCH}(\mathrm{t})$ & $99.5 \%$ & $94.73 \%$ & $89.07 \%$ \\
\hline
\end{tabular}

The accuracy of the value at risk (VaR) prediction can be known through the correct VaR proportion [19]. The Correct VaR proportion is a method of determining VaR accuracy by looking at the actual loss proportion less than or equal to the $\mathrm{VaR}$ prediction. The correct $\mathrm{VaR}$ of the three stocks in this study can be seen in table 4 .

According to [16], a good VaR estimation method can be determined from the correct VaR. If the difference between the correct $\mathrm{VaR}$ and the significance level $(\alpha)$ is the smallest, then the model has a good 'performance' in predicting future values. Based on table 4, it is found that INDF.JK stock with 
a significance level of $99 \%$ GARCH with a student-t error distribution is more suitable to describe INDF.JK stock returns than GARCH with a normal error distribution. Meanwhile, with a significance level of $95 \%$ and $90 \%$, GARCH with a normal error distribution is more suitable than GARCH with a student-t error distribution. In GSPC stocks, the model that best fits the data is the $\operatorname{GARCH}(1,1)$ model, with the error being normally distributed.

\section{CONCLUSION}

Based on the research results, it is found that the GARCH $(1,1)$ model can be used to model the stock returns of IBM, INDF.JK and GSPC. There is no significant difference between the GARCH $(1,1)$ model with a normally distributed error and GARCH $(1,1)$ with a student-t distribution error in determining the prediction of $\mathrm{VaR}$ values. It is known from the difference between the predictions of the two models, which is relatively small, only $\pm 10-3$. The predictive accuracy of the Value at Risk value can be determined by determining the correct $\mathrm{VaR}$ proportion. The simulation results of the three stocks in this study indicate that, in general, the prediction of Value at Risk using the GARCH model with a normally distributed error is more accurate than the GARCH model with a Student-t distribution error. There have been many developments from experts regarding the GARCH volatility model. Research can be continued using these models, such as the integrated GARCH model, the stochastic $\mathrm{GARCH}$, and others.

\section{REFERENCES}

[1] Bursa Efek Indonesia. (2021). Indeks, IDX. https://www.idx.co.id

[2] Alexander, C. 2008. Pricing, Hedging and Tranding Financial Instrument. Jhon Wiley and Sons.

[3] Franses, P. H., Vanderleij, M., \& Paap, R. (1987). Asimple Test for GARCH Against A Stochastic Volatility. Journal of Financial Econometrics, 6. 291-301.

[4] Dennis, S. A., \& Sim, A.B. (1999). Share Price Volatility with The Introduction of Individual Share Futures on The Sydney Futures Exchange. International Riview of Financial Analysis, 8(2). 153-163.

[5] Hull, J., \& White, A. (2000). Valuing Credit Default Swaps I: No Counterparty Default Risk. Journal of Derivatives, 8. 1-35.

[6] McKenzie, M.D., Brailsford, T.J., \& Faff, R.W. (2001). New Insights Into The Impact of The Introduction of Futures Tranding on Stock Price Volatility. The Journal of Futures Market, 21(3). 237-255.

[7] Hung, M.W., Lee, C.F., \& So, L.C. (2003). Impact of Foreign-listed Singel Stock Futures on The Domestic Underlying Stock Market. Applied Economics Letters, 10(9). 567-574.

[8] Posedel, P. (2005). Properties and Estimation of GARCH(1,1) Model. Metodoloski Zvezki, 2. 243-257.

[9] Tsay, R. 2005. Analysis of Financial Time Series. John Wiley and Sons.

[10] Cont, R. (2001). Empirical Properties of Asset Return: Stylized Facts and Statistical Issue. Quantitative Finance, 1. 223-23

[11] Enggel, R. F., Patton, A.J. (2001). What Good is A Model?. Quantitative Finance, 1. 237245.

[12] Bollerslev, T. (1986). Generalized Autoregressive Conditional Heteroskedastic. Journal of Econometrics, 31. 307-327.

[13] Floros, C. (2007). The Use of GARCH Model for The Calculation of Minimum Capital Risk Requirements: International Evidence. International Journal of Managerial Finance, 3(4). 360-371.

[14] Beer, J. (2009). Changes in The Volatility Level and Structure of Shares Post Single Stock Futures Tranding. Journal Corporate Ownership \& Control, 7(2). 296-310.

[15] Bohl, M.T., Diesteldorf. J., \& Siklos, P.L. (2015). China Economic Riview, 34. 207-224.

[16] So, M. K. ., \& Yu, P. L. (2006). Empirical Analysis of GARCH Models in Value at Risk Estimation. Journal of International Financial Market Institution and Money, 16. 180-197.

[17] Engle, R. F., \& Bollerslev, T. (1986). Modeling The Persistence of Conditional Variance. Econometric Riview, 5. 1-50.

[18] Nelson, D. (1991). Conditional Heteroskedasticity in Asset return: a new approach. Econometrica, 59. 347-370.

[19] Wong, M.C.S., Cheng, W.Y., \& Wong, C.Y.P. (2003). Market Risk Management of Bank: Implication from The Accuracy of Value-at-Risk Forecasts. Journal of Forcasting, 22(1). 23-33.

[20] McNail, A.J., Frey, R., Embrechts, P. (2005). Quantitative Risk Management. United Kingdom: Princeton University Press.

[21] Taylor, S.J. (2008). Modeling Financial Time Series. United States of America: Word Scientific Publising Co. Re. Ltd. 